\title{
Family Planning and Health Commodities Security in Nepal
}

\author{
Shakya HS, ${ }^{1^{*}} \mathrm{KC} \mathrm{NP}^{2}$ \\ ${ }^{1}$ USAID | DELIVER PROJECT/John Snow Inc.,
}

${ }^{2}$ Logistics Management Division, Department of Health Services, Ministry of Health and Population, Nepal

\author{
*Corresponding Author: \\ Heem Sunder Shakya, \\ USAID | DELIVER PROJECT, \\ Hotel Oasis Complex, 3rd Floor, Patan Dhoka, \\ PO Box 2901, Kathmandu, Nepal. \\ Email: heemshakya@gmail.com
}

\section{Citation}

Shakya HS, KC NP. Family Planning and Health

Commodities Security in Nepal. Nepal Journal of Medical

Sciences 2014;3(1):51-6

\begin{abstract}
Background: Commodity security is essential for effective delivery of quality health services. Commodity security exists when people are able to choose, obtain and use products whenever they need them. With leadership of Government of Nepal's Logistics Management Division and with technical assistance from United States Aid for International Development funded projects have been consistently working toward this goal with priority to Family Planning (FP), Reproductive Health, and Maternal Child Health commodities.
\end{abstract}

Methods: A National Consensus Contraceptive Security Forecast meeting is held annually at center. The meeting is participated by Regional, District, Program Divisions, National Planning Commission, Ministry of Finance, External Donor Partners, Social Marketing agencies, and Non Governmental Organizations (NGO). The quantity needed, shipment schedule, funding requirement and funding shortfall, distribution and storage strategies for the Public, Social Marketing, and NGO sectors are presented for next five years.

Results: With secured funding, increased availability of family planning commodities (stock-outs rate is less than $2 \%$ ) at service delivery sites have contributed to improve national health indicators like Total Fertility Rate and Contraceptive Prevalence Rate. Key program interventions have ensured FP commodity security through effective coordination of public, private and external donor partners.

Conclusion: Key lessons learned was a spirit of 'Teamwork' and good coordination -active involvement of other stakeholders is essential for ensuring FP commodity security. Other was an importance of 'Advocacy' for commodity security at district, regional and central levels of government and among stakeholders. Challenges are complexity of public procurement procedure and frequent transfer of trained staff, and distribution and transportation of health commodities from district to health facilities still poses a challenge to supply chain management.

Keywords: Commodities security; pipeline; quantification and forecasting; stock-outs 


\section{Background:}

Commodity security is essential for effective delivery of quality health services. Commodity security exists when people are able to choose, obtain and use products whenever they need them. ${ }^{1}$ With the leadership of Logistics Management Division (LMD)/MoHP and with technical assistance from United States Aid for International Development (USAID) funded projects (DELIVER and Nepal Family Health Program) have been consistently working toward this goal with priority to Family Planning (FP) commodities, reproductive health and maternal child health commodities.
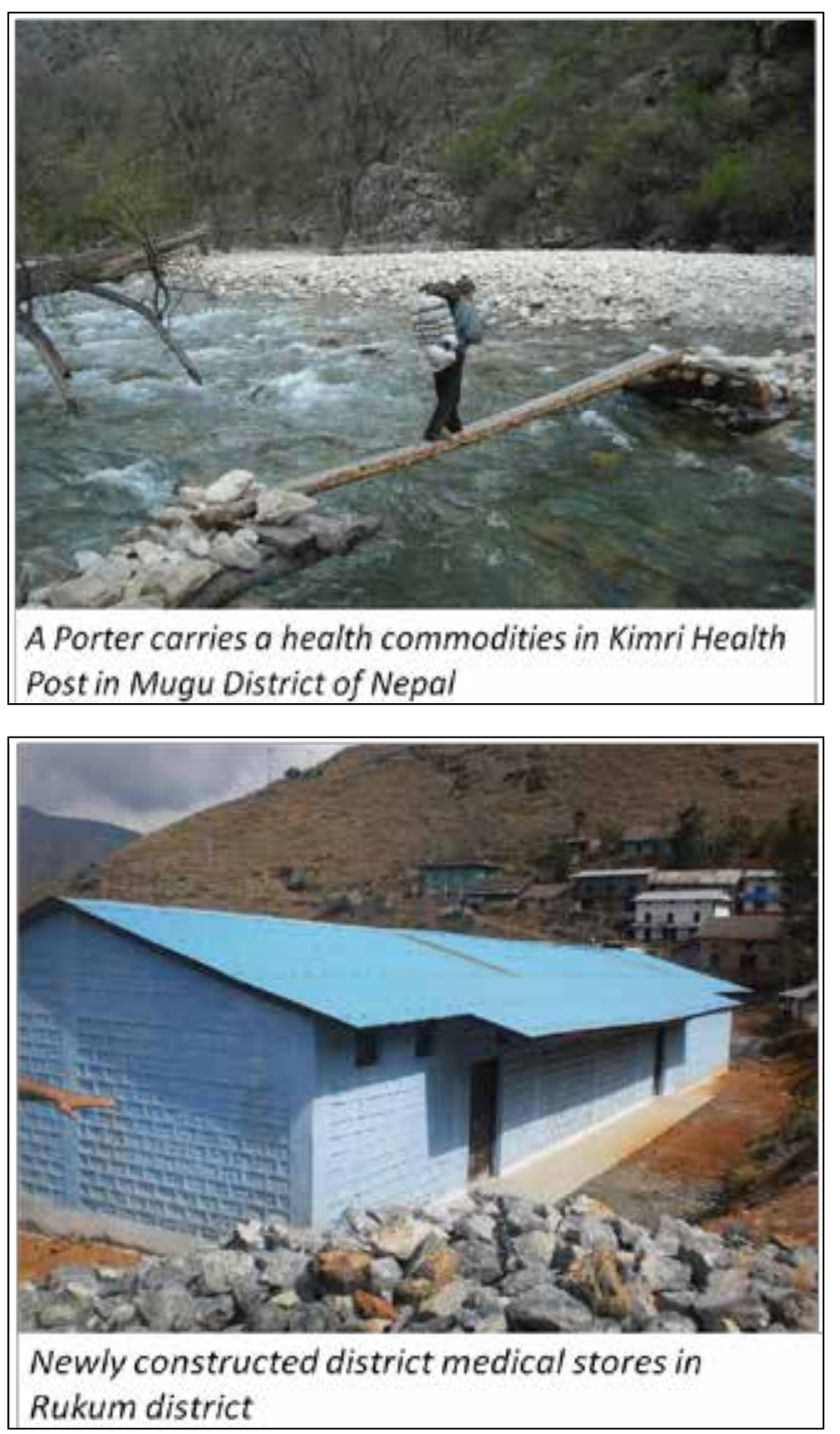

National Logistics Management Information System (LMIS), a quarterly reporting system from all service delivery point was established in 1995/96 with technical and financial support from USAID \{John Snow Inc. (JSI)\}, which is now become a key provider of information for logistics decision making for LMD. The Contraceptive Security Working Group was formed under the leadership of the Family Health Division (FPAN) and LMD in 2000. The core group consisted of representations from USAID, United Nations Population Fund (UNFPA), DELIVER, Nepal Family Health Program, and Kreditanstalt für Wiederaufbau (KfW) which is a German governmentowned development bank, based in Frankfurt. Larger group consists of representation from the core group plus members from National Planning Commission, Ministry of Finance, FPAN, Social Marketing Agency, and the National Center for AIDS and Standard Control (NCASC).

\section{Program Intervention}

The success of FP commodity security in Nepal can be attributed to excellent team work of various MoHP Program Divisions (FHD, LMD, CHD, NCASC), external donor partners (USAID, UNFPA, KfW, DFID, World Bank, UNICEF), and stakeholders (social marketing agencies and FPAN). Some of the key program interventions contributing to success of the FP commodities securities are - practice of forecasting and quantification at the national level, scale up of pull system, strengthening district warehouses, and capacity building in Government of Nepal's (GoN's) staff on logistics management.

Some of the key program interventions contributing to success of the FP commodities securities are briefly described below. These program interventions are nationwide and targets GoN's staff working at central, regional, district, and health facilities level.

(i) LMIS, Forecasting, and National Pipeline Review and monitoring: Implemented in 1994, the Logistics System Implementation Plan (LSIP) piloted the LMIS in four Eastern districts ${ }^{2}$. A well functioning, integrated, and robust LMIS is reliable, effective, and used for logistics decision-making, forecasting, inventory management, pipeline monitoring, procurement and prevention of stock-outs at health facility level. Monitoring and using LMIS data for informed decision-making ensures availability of health commodities. In 2009/10 LMD implemented web-based LMIS and Inventory Management System at District and Regional Level. LMD conducts annual forecast workshop and quarterly national pipeline review meetings of FP and other key program commodities for procurement, shipment, and distribution decisions. (For detail reading ${ }^{3,4}$ )

(ii) Infrastructure (Storage Facilities): Good storage practice helps ensure the quality of drugs and other commodities and improves their distribution to service delivery sites. And good storage facilities are the key to 


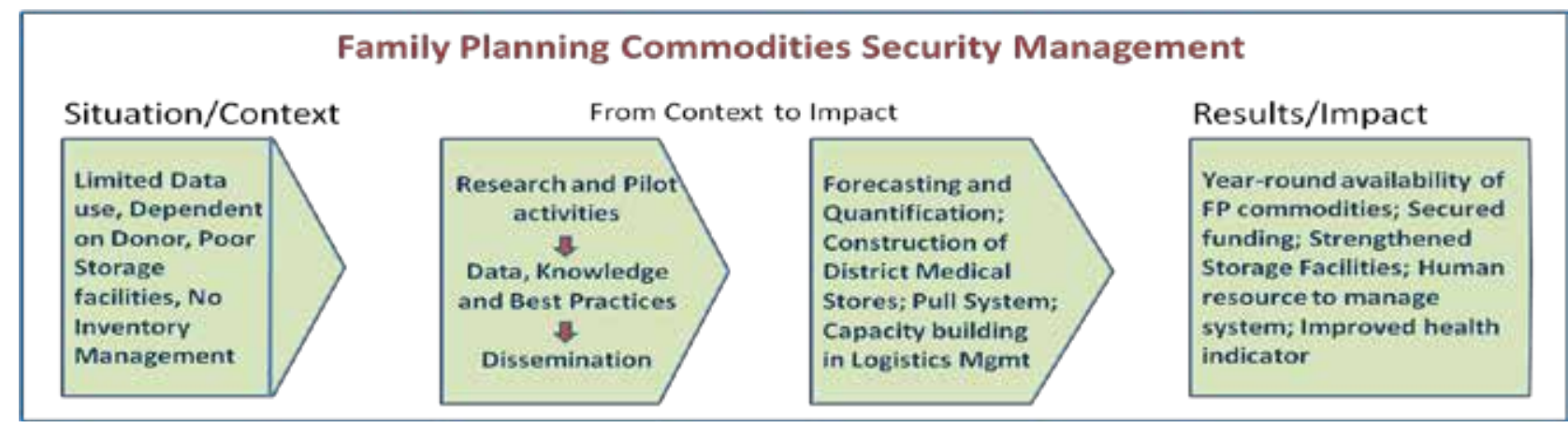

facilitate these processes. Improvement, strengthening and construction of district warehouses begun with the initiation of USAID/JSI and LMD for need of good warehouses in the districts in 2001. At present, 54 District Warehouses constructed (KfW-43, DFID-5, GoN-6). One cold chain warehouse (KfW fund) built in Pathalaiya Transit Warehouse complex. Increased total storage space from 21,223 sq. ft. from 1999 to 86,400 sq. $\mathrm{ft}$. in 2011. Safe storage of valuable health commodities maintaining storage standards. Decreased wastage and expiry of drugs. 18 are under construction from GON's Fund, expected to be completed by 2013/14. (For detail reading ${ }^{5}$ )

(iii) Inventory Control System (Pull System) in all 75 districts: In 1998, an inventory control system was developed and implemented in all districts and health facilities (HFs). The system not only allowed HFs to determine the quantity of program commodities that can be ordered from the district store but also set the authorized stock level and emergency order point used to trigger re-orders. And demand based Pull System for Essential Drugs was implemented in 2005/06 and completed in all 75 districts in 2009/10. (For detail reading ${ }^{6,7}$ )

(iv) Capacity Development in Health Logistics: Health workers in public health facilities needed updating of their knowledge and skills in health logistics management including on Pull System. DELIVER, NHTC and LMD have worked to institutionalize logistics and LMIS training. Trainers from NHTC were trained and Regional Health Training Centers have been conducting logistics training at HFs. Logistics training was included in NHTC's annual work plan and endorsed by the National Planning Commission. Logistics practices and LMIS system have been incorporated in pre- and in-service training curricula of NHTC staff and the pre-service training of health workers and public health graduates. Since 2002, number of health workers trained in basic health logistics management has reached to 16,730 .

Methods:

A National Level Consensus Contraceptive Security Forecast workshop is held annually at Center. The workshop is participated by Regional, District, Program Divisions, National Planning Commission, Ministry of Finance, External Donor Partners, Social Marketing agencies, and Non Governmental Organizations (NGO). The quantity needed, shipment schedule, funding requirement and funding shortfall for the Public, Social Marketing, and NGO sector (FPAN) sectors are presented for next five years. DELIVER project provides technical support in facilitating the workshop, drafting five years Forecast Report for family planning, maternal and child health commodities, vaccines, Essential Drugs and ARVs. The Forecast Report identifies the long-term costs and requirements for FP and other commodities, allowing better identification of funding gaps and procurement and distribution schedules. This exercise also helps program divisions to identify quantity and funding need for their annual work plan activities. And in each quarter a National Pipeline meeting takes place at LMD to review, monitor, and evaluate the procurement, shipment, distribution and transportation status of FP and other health commodities. Intended beneficiaries of this program are population of the entire country.

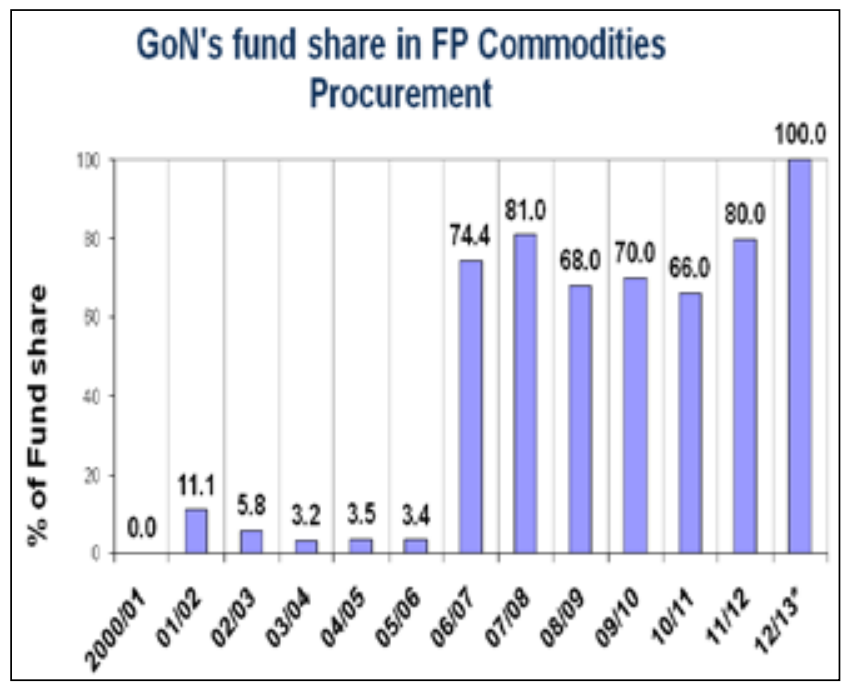




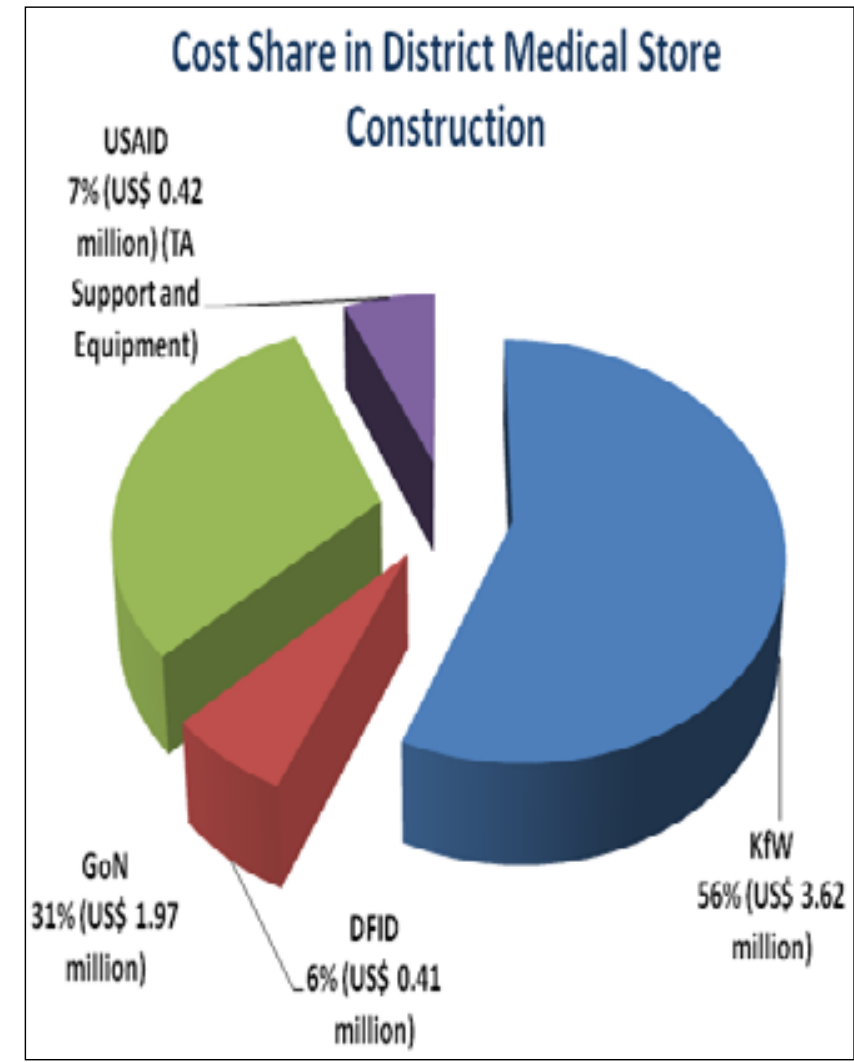

Data Source: LMIS/Logistics Management Division/MoHP

\section{Results:}

- With secured funding, increased availability of family planning commodities (currently the stock-outs rate of FP commodities at service delivery sites is less than $2 \%$ ) at the service delivery sites have contributed to improve national health indicators like Total Fertility Rate and Contraceptive Prevalence Rate

- With years of practice of quantification and forecasting, quarterly national pipeline review meetings, and other key program interventions has ensured FP/ Maternal Neonatal Child Health (MNCH) commodity security through effective coordination of public, private and external donor partners

- The GoN's share in the funding of FP commodities has significantly increased since 2002 (0\% in $2000 / 01$ to $80 \%$ in $2011 / 12$ )

- The practice has helped GoN in allocating and finding needed resources for construction of district medical stores, procurement of FP commodities, inventory management, budget for distribution and transportation of commodities to health facilities

- The working group successfully developed a National Strategy on Reproductive Health Commodity Security for Nepal, 2007 - 2011.
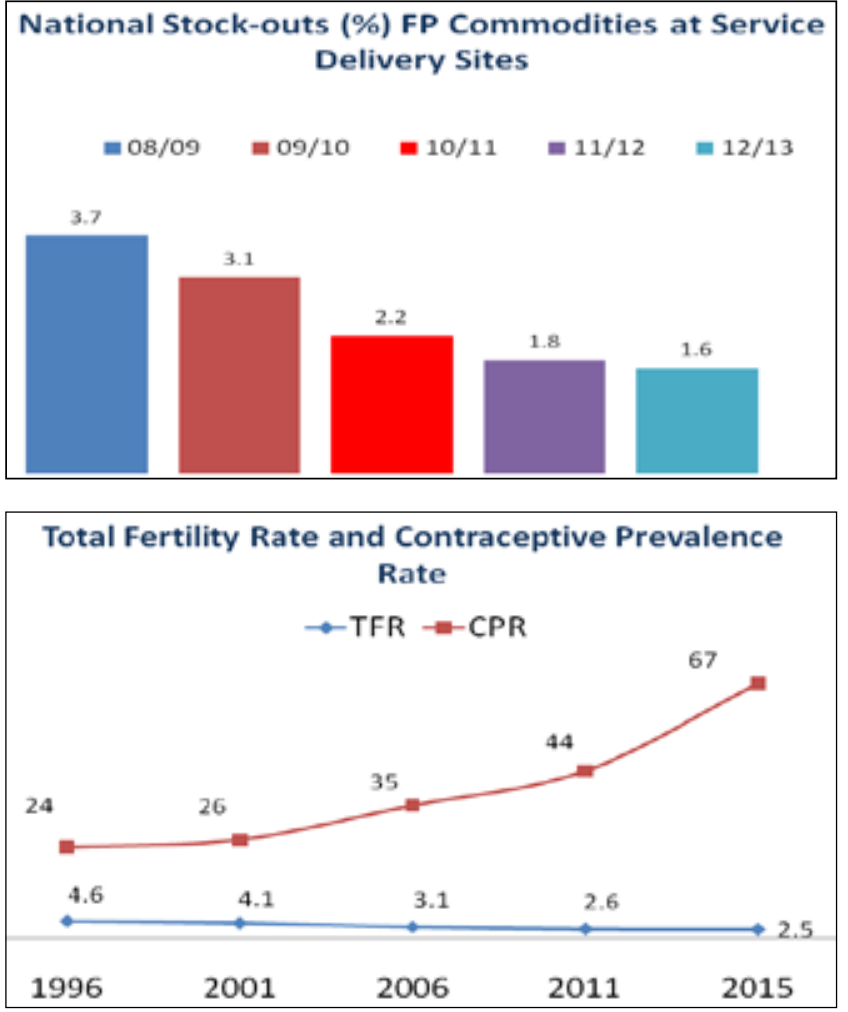

Data Source: LMIS/LMD and Demographic Health Survey (DHS)/Nepal
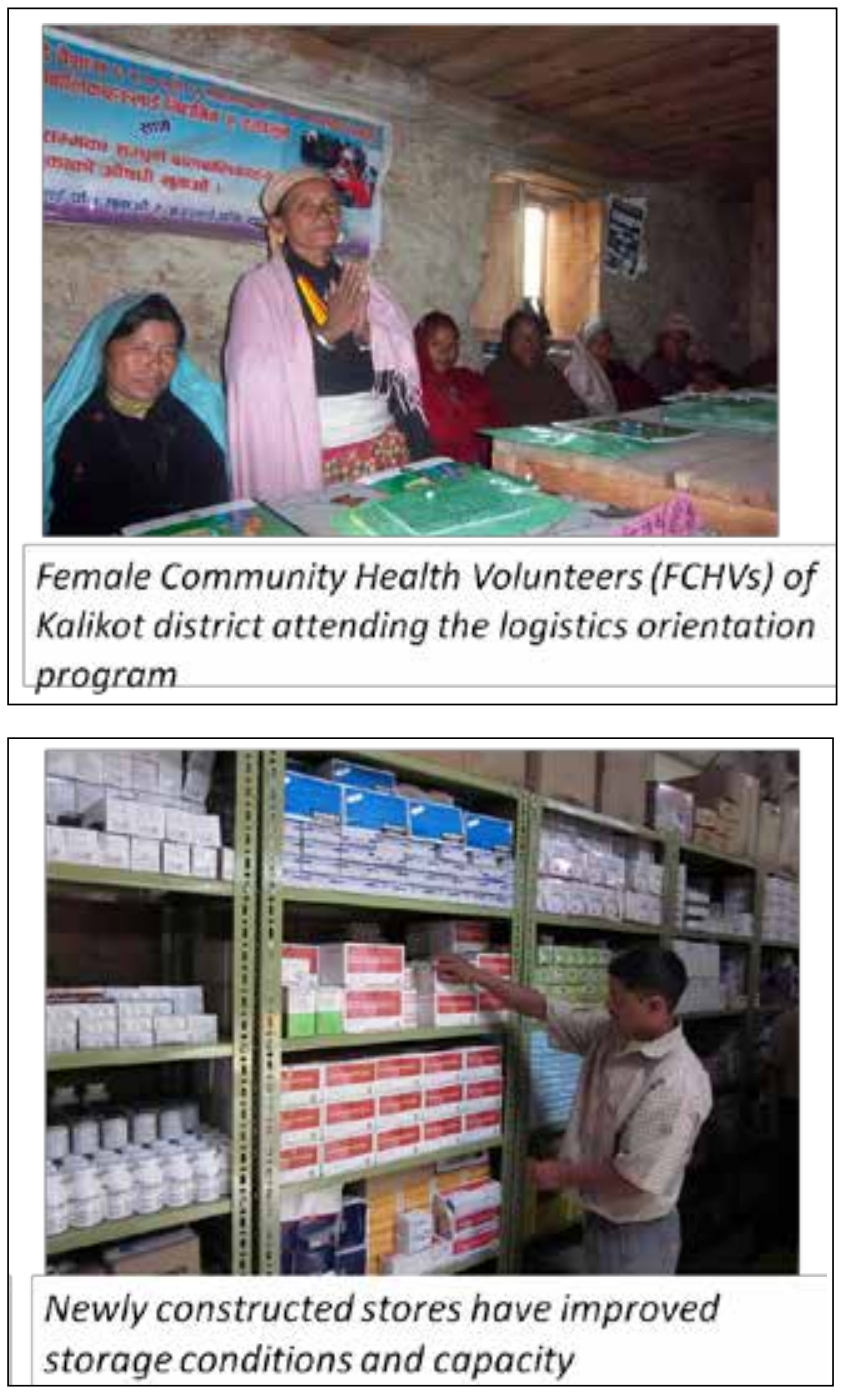


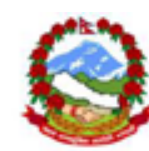

\section{Status of Construction of} District Medical Warehouse, 2013

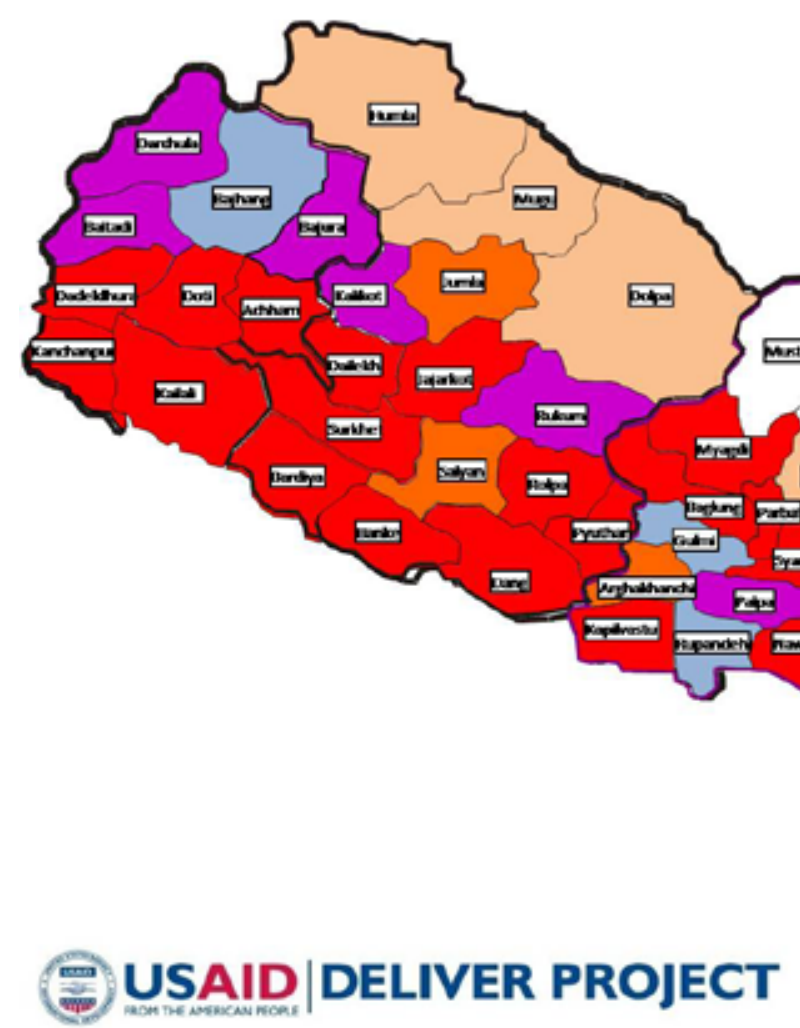

Lessons Learned / Challenges:

- One of the key lessons learned was a spirit of 'teamwork' and good coordination and active involvement of other stakeholders is essential for ensuring FP commodity security

- Importance of 'advocacy' for commodity security at district, regional and central levels of government and among stakeholders is a major factor in achieving FP commodities security in the country

- The practice has led to replicate the process (quantification, forecasting, pipeline monitoring) for MNCH commodities, Vaccines, Essential Drugs and ARVs, which will lead to better commodity security in other program

- Challenges to attain a 'total' health commodities security in Nepal (stock-out rate for selected Essential Drugs are still as high as $25 \%$ each quarter in health facilities $)^{7}$

- Complexities of public procurement procedures (frequent delays)

- Local level (District and Regional) procurement

\section{KFW DFID}
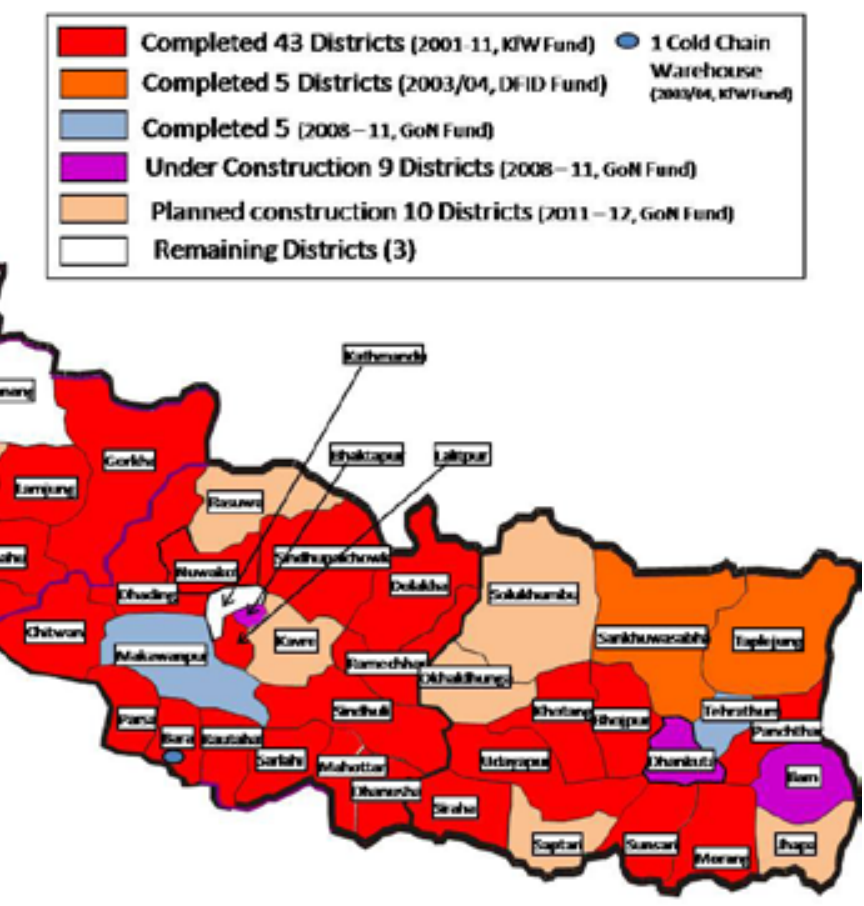
Area $=$ INTL\&id $=12151 \&$ thisSection $=$ Resources

4. Nepal: Transforming Decision Making with web-based LMIS. Available at; http://nfhp.jsi.com/Res/Docs/ NPLMISFinal.pdf

5. NFHP Technical Brief 14: District Store Construction. Available at; http://www.jsi.com/JSIInternet/ Resources/publication/display.cfm?txtGeoArea=INTL\&id=12153\&thisSection= Resources

6. NFHP Technical Brief 13: Pull System. Available at; http://www.jsi.com/JSIInternet/Resources/publication/ display.cfm?txtGeoArea=INTL\&id=12152\&thisSec- tion $=$ Resources

7. New Demand-Based Supply Chain Model Yields Health Benefits in Nepal. Available at;

http://nfhp.jsi.com/Res/Docs/NPPullSystem.pdf

8. Shakya HS, Adhikari S, Gurung G, et al. Strengthening National Health Systems for Improving Efficiency of Health Service Delivery in Nepal. Available at;

http://nfhp.jsi.com/Docs/StrengtheningNationalHealthSystemsforImprovingEfficiencyofHealthServiceDeliveryinNepal.pdf 